DOI: https://doi.org/10.24867/09MO03Maravic

\title{
SISTEMATSKA ANALIZA MOGUCNOSTI TRETMANA I PROCENA KOLIČINA OTPADNOG MULJA IZ KOMUNALNIH OTPADNIH VODA
}

\section{SYSTEMATIC ANALYSIS OF TREATMENT POSSIBILITIES AND ESTIMATION OF QUANTITIES OF WASTE SLUDGE FROM MUNICIPAL WASTEWATER}

\author{
Marko Maravić, Srđan Kovačević, Nemanja Stanisavljević, Fakultet tehničkih nauka, Novi Sad
}

\section{Oblast: INŽENJERSTVO ZAŠTITE ŽIVOTNE SREDINE}

Kratak sadržaj - U radu je urađena procena količine otpadnog mulja koji bi se generisao u planiranih 200 postrojenja za preradu otpadnih voda (PPOV) koja treba da se izgrade na teritoriji AP Vojvodine, kao $i$ tehnologijama njegove prerade, načinima održive upotrebe (cirkularna ekonomija mulja) i načinima bezbednog odlaganja.

Ključne reči: PPOV; otpadni mulj; anaerobna digestija; cirkularna ekonomija; biogas.

Abstract - In this paper, an assessment was made of the possible amount of sludge that will be generated by the operation of the 200 wastewater treatment plants (WWTPs) that are planned to be built, as well as the technologies of its processing, ways of sustainable use (sludge circular economy) and ways of safe disposal.

Keywords: WWTP, sludge; anaerobic digestion; circular economy; biogas.

\section{UVOD}

Zbog potrebe Srbije za dostizanjem EU standarda tretmana i zaštite voda, planira se izgradnja oko 200 PPOV na teritoriji AP Vojvodine. Otpadne vode sadrže veliki broj različitih jedinjenja, čvrstih materija (350-1200 $\mathrm{mg} / \mathrm{l}$ ), rastvorenih materija (HPK 250-1000 mg/l), mikroorhanizama, nutrijenata, teških metala i mikropolutanata [1].

Kao rezultat prečišćavanja otpadnih voda, dobija se sa jedne strane voda koja je bezbedna za ispuštanje $u$ vodne recipijente, a sa druge strane ostaje otpadni mulj, koji predstavlja mešavinu vode (u različitim odnosima 2095\%), živih i mrtvih mikroorganizama, organskih materija, organskih i neorganskih hemijskih jedinjenja [2]. Ovaj dobijeni mulj se mora preraditi kako bi se bezbedno odložio ili se može koristiti za dobijanje energije, biogoriva, bioplastike, kao fertilizator u poljoprivredi itd.

\section{KARAKTERISTIKE MULJA}

Otpadni mulj nastao u PPOV može se podeliti prema tipu tehnološkog procesa $\mathrm{u}$ kom je nastao na primarni, sekundarni (ili biološki) i hemijski. „Sirovi mulj“ (engl. Raw sludge) je mulj koji još nije tretiran biološkim ili

\section{NAPOMENA:}

Ovaj rad proistekao je iz master rada čiji mentor je bio dr Nemanja Stanisavljević. hemijskim tretmanom radi otklanjanja ili smanjenja koncentracija čvrstih i organskih materija ili patogena. Kada se izvrši tretman mulja, dobija se tzv. tretirani mulj (eng. biosolid) koji se može klasifikovati tretmanom, kao što su: (I) Aerobno digestirani; (II) Anaerobno digestirani (AD); (III) Alkalno stabilizovani; (IV) Kompostirani; (V) Termički osušeni [3].

\subsection{Količina proizvedenog mulja}

Određivanje količine mulja koja će biti generisana $u$ PPOV je veoma važno za projektovanje sistema za prihvat, obradu i odlaganje muljeva iz prečišćavanja otpadnih voda [3].

Najbolji pristup za procenu generisane količine mulja je baziranje na podacima iz sličnih postrojenja (veličina, tehnološki proces, karakteristike otpadne vode) i očekivanoj količini otpadne vode za tretiranje.

Specifična težina mulja se može i izračunati po sledećoj formuli (formula 1) [4]:

$$
\begin{aligned}
& \text { Specifična težina mulja } \\
& =\frac{1}{\left(\frac{\% \text { SM u mulju }}{\text { Gustina mulja }}+\frac{\% \text { vode u mulju }}{1.0}\right)}
\end{aligned}
$$

Inkorporiranje čvrstih materija u mulj poznato je i kao hvatanje (engl. solids capture).

Obično se izražava u procentima sa ciljem da se prikaže efikasnost inkorporiranja čvrstih materija u mulj koji će potom biti tretiran u narednim fazama prerade.

Opterećenje čvrstom materijom [kgSS/dan] možemo predstaviti preko izraza 2 i 3 [4]:

Effluent SS load in sludge $=$ Solids capture $\times$ Influent SS load in sludge

SS load in drained liquid $=$ (1 - Solids capture $) \times$ Influent SS load in sludge

\subsection{Proizvodnja primarnog mulja}

Količina mulja koji se generiše tokom primarne obrade zavisi pre svega od efikasnosti uklanjanja suspendovanih materija (engl. suspended solids, SS) u primarnim taložnicima.

Tipična efikasnost u uklanjanju (hvatanju) SM u primarnim taložnicima je 60 do $65 \%$. stopa uklanjanja SM može povezati sa vremenom hidrauličkog zadržavanja ili sa površinskim prelivanjem primarnog taložnika (engl. primary clarifier). 


\subsection{Proizvodnja aktiviranog mulja}

$\mathrm{U}$ postupku sa aktivnim muljem, važne promenljive $\mathrm{u}$ kvantifikaciji proizvedenog mulja su: količina uklonjenog supstrata (BPK ili HPK), masa mikroorganizama u sistemu i nebiorazgradiva inertna SM. Računanje neto rasta biomase i količine otpadnog aktiviranog mulja (WAS) vršimo preko izraza 4 i 5 [5]

$$
\begin{gathered}
P_{x}=Y\left(S_{0}-S\right)-k_{d} X \\
W A S=P_{x}+I_{0}-E_{t}
\end{gathered}
$$

$P_{x}-\quad$ neto rast biomase izražen kao isparljive čvrste supstance $(V S S, k g / d)$

$Y$ - koeficijent bruto prinosa $(\mathrm{kg} / \mathrm{kg})$

$S_{0}-\quad$ Influent supstrat (BPK ili $H P K, \mathrm{~kg} / \mathrm{d}$ )

$S$ - Efluent supstrat (BPK ili HPK, $\mathrm{kg} / \mathrm{d}$ )

$k_{d}-\quad$ Koeficijent endogenog raspadanja $\left(d^{-1}\right)$

$X-\quad$ Biomasa u aeracionom bazenu (MLVSS, $\mathrm{kg}$ )

Vreme zadržavanja mulja (engl. Solids Retention Time, $S R T$ ) poznato još i kao starost mulja (engl. sludge age) je veoma važan parametar u procesu biološkog prečišćavanja aktiviranim muljem. SRT predstavlja prosečno vreme zadržavanja mulja u sistemu i predstavlja se u danima.

\section{OBRADA MULJEVA}

Osnovni problem sa muljem je njegova velika masa, od čega je velika većina voda. Većina muljeva je u stvari oko 99\% vode [4]. Primarni ciljevi tretmana mulja su smanjenje mase/zapremine uklanjanjem vode $\mathrm{i}$ gde je to moguće, obnavljanje resursa.

\subsection{Stabilizacija muljeva}

Ciljevi stabilizacije muljeva su: (I) smanjenje broja patogena, (II) eliminisanje neprijatnih mirisa, (III) inhibicija, smanjenje ili eliminacija truljenja mulja [3]. Preživljavanje patogena, emisija neprijatnih mirisa i proces truljenja nastaju kada se mikroorganizmima $u$ mulju omogući da se nesmetano umnožavaju koristeći organsku frakciju mulja kao supstrat. Načini da se eliminišu ti negativni efekti usmereni su uglavnom na biološko smanjenje sadržaja organske materije i dodavanje hemikalija u muljeve, kojim se ostvaruje sredina nepovoljna za preživljavanje mikroorganizama $u$ mulju. Sem navedenih efekata, stabilizacija muljeva može da smanji zapreminu mulja, produkuje upotrebljivi biogas i poboljša obezvodnjavanje mulja.

Kada se projektuje proces stabilizacije, važno je da se uzme u obzir količina mulja koja se obrađuje, integrisanje procesa stabilizacije u okviru PPOV, kao i ciljevi procesa stabilizacije. Ciljevi su obično definisani odgovarajućom regulativom, kao i načinom konačnog odlaganja mulja. U slučaju odlagati na zemljište, smanjenje broja patogena mora biti uzeto u obzir.

\subsubsection{Anaerobna stabilizacija}

Anaerobna stabilizacija ili digestija (od engl. digestion) je proces anaerobne razgradnje organskih materija u mulju. Biološki proces anaerobne digestije, koji provode različite fakultativno i obligatno anaerobne bakterije, sastoji se od tri faze: (I) hidrolize polimernih konstituenata, (II) fermentacije nastalih produkata hidrolize, pri čemu dominantno nastaju organske kiseline kratkih lanaca (acidogeneza) i (III) metanogeneza, odnosno biološka konverzija produkata acidogeneze u biogas - smešu metana i ugljendioksida [3]. Najvažniji faktori koji utiču na odvijanje procesa anaerobne digestije su: (I) vreme zadržavanja čestica u anaerobnom reaktoru (digestoru), (II) hidrauličko vreme zadržavanja mulja u digestoru, (III) temperatura na kojoj se mulj obrađuje u digestoru, (IV) alkalitet mulja, (V) $\mathrm{pH}$ mulja, (VI) prisustvo inhibitornih supstanci u mulju koji se stabilizuje [3].

\section{KOLIČINE MULJA DOBIJENE IZ PPOV U AP VOJVODINI}

Upravljanje muljem proizvedenim u PPOV predstavlja jedan od najtežih problema koje treba rešiti. Mulj proizveden u PPOV predstavlja samo nekoliko procenata zapremine prerađenih otpadnih voda (nakon obezvodnjavanja i ugušćivanja), ali njegova obrada i odlaganje čini i do $50 \%$ ukupnih operativnih troškova.

Za računanje (teorijske) količine mulja koja će biti proizvedena kao rezultat prerade otpadne vode, koristićemo podatke iz tabele 1 .

Tabela 1 - Karakteristike i količine mulja proizvedenog

\begin{tabular}{|c|c|c|c|}
\hline \multirow[b]{2}{*}{$\begin{array}{c}\text { Tehnološki proces } \\
\text { u PPOV }\end{array}$} & \multicolumn{3}{|c|}{$\begin{array}{l}\text { Karakteristike proizvedenog mulja iz } \\
\text { otpadnih voda }\end{array}$} \\
\hline & $\begin{array}{l}\text { Sadržaj } \\
\text { suve } \\
\text { materije } \\
(\%)\end{array}$ & $\begin{array}{l}\text { Masa mulja } \\
(\mathrm{gSM} / \mathrm{ES} \cdot \text { dan })\end{array}$ & $\begin{array}{l}\text { Zapremina } \\
\text { mulja } \\
(\mathrm{L} / \mathrm{ES} \cdot \mathrm{dan})\end{array}$ \\
\hline $\begin{array}{l}\text { Aktivirani mulj } \\
\text { - Primarni } \\
\text { mulj }\end{array}$ & $2-6$ & $35-45$ & $0.6-2.2$ \\
\hline $\begin{array}{l}\text { - } \quad \text { Sekundarni } \\
\text { mulj }\end{array}$ & $0.6-1$ & $25-35$ & $2.5-6.0$ \\
\hline • Ukupno & $1-2$ & $60-80$ & $3.1-8.2$ \\
\hline $\begin{array}{l}\text { Aktivirani mulj sa } \\
\text { produženom } \\
\text { aeracijom }\end{array}$ & $0.8-1.2$ & $40-45$ & $3.3-5.6$ \\
\hline Aerisana laguna & $6-10$ & $8-13$ & $0.08-0.22$ \\
\hline
\end{tabular}
različitim procesima [4]

\section{VREDNOST OTPADNOG MULJA U KONTEKSTU CIRKULARNE EKONOMIJE}

Povećanje količine mulja iz tretmana otpadnih voda je globalni problem u kontekstu rasta populacije i adekvatne sanitarne zaštite. Mada se mulj smatra otpadom, može se koristiti kao izvor energije ili resursa, zamenjujući na taj način ekvivalentnu količinu materijala i/ili energije koja bi se inače trebala obezbediti iz neobnovljivih izvora. načini tretmana i odlaganja mulja su veoma važni za zaštitu životne sredine, pre svega zbog mogućih organskih zagađivača, teških (i toksičnih) metala i patogena koji mogu zaostati u mulju, koji mogu izazvati zdravstvene probleme.

Cirkularna ekonomija predstavlja antitezu dosadašnjem linearnom modelu privrede, koji podrazumeva nekontrolisanu eksploataciju prirodnih resursa i protok materijala od fabrike preko korisnika do deponije. Prema Ellen MacArthur fondaciji (EMF), kružna ekonomija je: rekonstruktivna i regenerativna po dizajnu i koja ima za cilj da proizvodi, komponente i materijali u svakom trenutku budu maksimalno korisni i vredni [7]. 
Tabela 2 - Kapacitet PPOV po oblastima AP Vojvodine u ES [6]

\begin{tabular}{lc}
\hline Oblast & Ukupan kapacitet [ES] \\
\hline Zapadno Bačka & 388.200 \\
Severno Bačka & 280.000 \\
Severno Banatska & 237.620 \\
Južno Bačka & 879.500 \\
Srednje Banatska & 214.300 \\
Južno Banatska & 394.000 \\
Sremska & 403.900 \\
\hline Ukupno & $\mathbf{2 . 7 9 7 . 5 2 0}$ \\
\hline
\end{tabular}

Tabela 3 - Količine proizvedenog mulja iz PPOV u Vojvodini po oblastima

\begin{tabular}{lccc}
\hline \multirow{2}{*}{ Oblast } & $\begin{array}{c}\text { Ukupan } \\
\text { kapacitet [ES] }\end{array}$ & \multicolumn{2}{c}{$\begin{array}{c}\text { Proizvodnja mulja u PPOV } \\
\text { [tona suvog mulja] }\end{array}$} \\
\cline { 3 - 4 } & & Dnevna & Godišnja \\
\hline $\begin{array}{l}\text { Južno } \\
\text { Bačka }\end{array}$ & 879.500 & 70 & 25.550 \\
$\begin{array}{l}\text { Južno } \\
\text { Banatska }\end{array}$ & 394.000 & 32 & 11.680 \\
$\begin{array}{l}\text { Severno } \\
\text { Bačka }\end{array}$ & 280.000 & 22 & 8.030 \\
$\begin{array}{l}\text { Severno } \\
\text { Banatska }\end{array}$ & 237.620 & 19 & 6.935 \\
$\begin{array}{l}\text { Srednje } \\
\text { Banatska }\end{array}$ & 214.300 & 17 & 6.205 \\
$\begin{array}{l}\text { Sremska } \\
\text { Zapadno }\end{array}$ & 403.900 & 32 & 11.680 \\
Bačka & 388.200 & 31 & 11.315 \\
\hline Ukupno & $\mathbf{2 . 7 9 7 . 5 2 0}$ & $\mathbf{2 2 3}$ & $\mathbf{8 1 . 3 9 5}$ \\
\hline
\end{tabular}

Zbog zakonodavstva koje ograničava odlaganje mulja na deponije, kao metode uklanjanja mulja, mnogi istraživači pokušali su naći ekološki održive načine za ponovnu upotrebu mulja. Evropska komisija smatra da ,ako otpad postane resurs koji će se vratiti u ekonomiju kao sirovina, tada treba dati mnogo veći prioritet ponovnoj upotrebi i recikliranju“" [8].

Ponovna upotreba mulja kao sirovine u različitim industrijama predstavlja odličan način za upravljanje otpadom, imajući u vidu koncept kružne ekonomije.

Uzimajući u obzir činjenicu da su organske komponente iz mulja značajan izvor resursa $u$ smislu energije i nutrijenata koji čekaju da budu iskorišćene, studija koju je 2015. godine realizovala Međunarodna asocijacija za čvrsti otpad (ISWA) [9], pokazuje da u kontekstu kružne ekonomije, korist od energije i goriva dobijenih iz otpada je što mogu da zamene druge energetske resurse i ograniče povezane emisije $\mathrm{CO}_{2}$.

\subsection{Povraćaj nutrijenata}

Znatne količine nutrijenata (približno $0,5-0,7 \%$ fosfora $\mathrm{i}$ 2,4-5,0\% azota) nalaze se u mulju, u obliku proteinisanih materijala koji mogu da se iskoriste za proizvodnju đubriva. Povraćaj i recikliranje fosfora smatra se mogućim pilotom, tj. slučajem na kom može da se „pokaže da cirkularni principi funkcionišu u praksi“ [7]. Kristalizacija je postupak koji se koristi za povraćaj fosfora iz PPOV u obliku struvita $\left(\mathrm{NH}_{4} \mathrm{MgPO} 4\right)$.

U istraživanju [10], pozivajući se na komunalnu otpadnu vodu sa $T S S$ od $26-30 \mathrm{~kg} / \mathrm{ES} / \mathrm{god}$. i tečnu frakciju iz primerne fermentacije celuloidnog mulja, procenjeno je da se može proizvesti $0,07-0,15 \mathrm{~kg} / \mathrm{ES} / \mathrm{god}$. struvita, što odgovara prihodu od $0,05-0,11 € / \mathrm{ES} /$ god.

\subsection{Građevinski materijal}

Kompleksi organskog ugljenika i neorganski kompoziti iz mulja predstavljaju izvor dragocenih materijala koji se pomoću termičke obrade mogu transformisati u proizvode kao što su veštački lagani agregati (engl. artificial lightweight aggregates), šljaku, opeku i staklo. Za proizvodnju opeke i cementa, mulj se može koristiti direktno bez spaljivanja. Dodavanje mulja u sirovom obliku proizvodnji cementa može biti alternativa postojećim metodama, eliminišući neke skupe i energetski intenzivne faze tretmana/odlaganja mulja. Još važnije je, što se otpad štetan po životnu sredinu može pretvoriti $u$ siguran i stabilan proizvod.

\subsection{Biogas}

Primarni izvor energije u PPOV je biogas proizveden $\mathrm{u}$ AD reaktorima, sa sadržajem metana (50-70\%) i ugljendioksida (30-50\%), kao i nekih tragova azota, vodonika, vodonik-sulfida i vodene pare. AD je jedna od najkorišćenijih tehnologija za proizvodnju biogasa $u$ PPOV. Uzimajući u obzir da se biogas može koristiti za dobijanje električne i toplotne energije, vodene pare i druge svrhe, njegova proizvodnja i maksimalno iskorišćenje je od esencijalnog značaja.

\section{ZAKLJUČAK}

Kada je tretman otpadnih voda u Vojvodini u pitanju, situacija je veoma loša. Obrađuje se oko $20 \%$ ukupnih otpadnih voda (komunalne + iz industrije), a otpadni mulj se odlaže na deponije. Pošto zakonska regulativa vezana za tretman i odlaganje mulja ne postoji, ne postoji ni način da se efikasno i bezbedno koristi, pre svega, $u$ poljoprivredi.

Kako možemo videti na slici 1 , stanje 2009. godine nije bilo baš pohvalno, a situacija se nije mnogo promenila $\mathrm{u}$ narednih 11 godina.

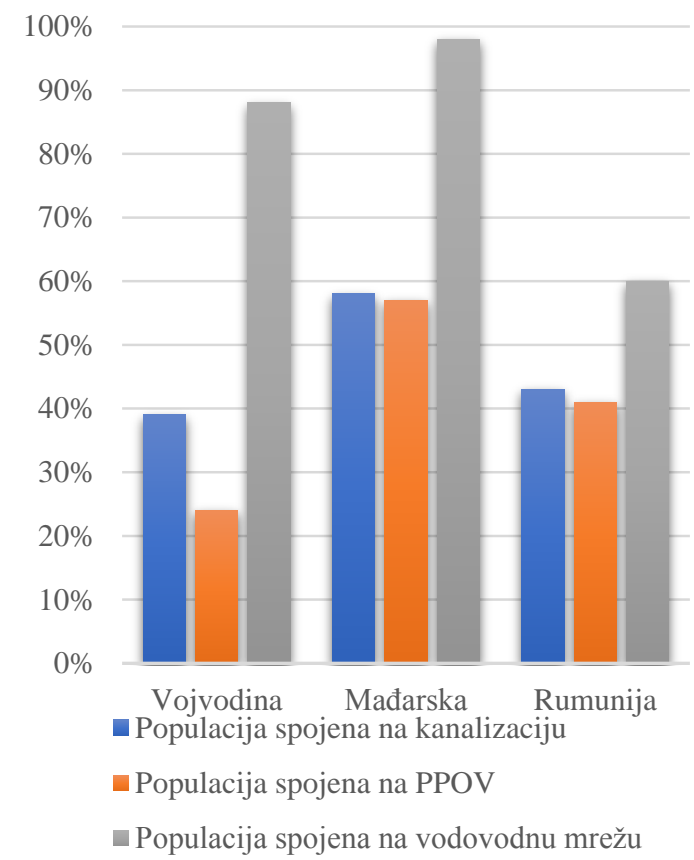

Slika 1. Stope priključenja na vodovod, kanalizaciju $i$ PPOV (2009.) [12] 
Zbog pregovora o pristupanju EU, Srbija mora da učini velike napore po pitanju upravljanja voda, a tretman otpadnih voda igra možda i najznačajniju ulogu. U sklopu napora da se trenutno stanje popravi, urađena je studija „Istraživanje i razvoj modela sakupljanja i tretmana otpadnih voda AP Vojvodine“ [6] u kojoj se razmatraju naselja za koja će se graditi PPOV, kao i potrebna veličina, tehnologije tretmana itd. Predviđena je izgradnja 195 PPOV za teritoriju Vojvodine.

Kako je prikazano u tabeli 2, predviđena PPOV bi trebalo da budu dovoljna za tretman 2.8 miliona ES, što se smatra dovoljnim računajući rast stanovništva i industrije $u$ narednih 30-tak godina. Na osnovu ovih parametara i podataka iz tabele 3, procenjeno je da će godišnja proizvodnja otpadnog mulja biti malo više od 81 hiljade tona (suvog mulja) godišnje.

Kada je u pitanju EU, podaci o upotrebi mulja i upotrebljenim tehnologijama u velikoj meri variraju. Procenjeno je da je 2008. godine, u 26 država članica EU proizvedeno više od 10 miliona tona suvog otpadnog mulja od kojih je 36\% upotrebljeno u poljoprivredi. Međutim, 5 od 26 zemalja (Nemačka, Engleska, Francuska, Italija i Španija) sudelovalo je sa čak 75\% u ukupnoj količini proizvodnje mulja [11].

Gledajući sve prethodno navedeno, možemo zaključiti da postoji realan potencijal za upotrebu otpadnog mulja u Vojvodini. Počevši od moguće upotrebe u AD procesima za dobijanje biogasa, ostatak mulja iz AD je odličan za upotrebu u poljoprivredi. Dobro obezvodnjen mulj se može koristiti i u industriji proizvodnje cementa ili u slučaju da se mulj spaljuje (zbog smanjenja konačne količine otpada) pepeo se može koristi u građevinskoj industriji prilikom proizvodnje opeke ili betona/maltera. $\mathrm{Ne}$ treba zaboraviti i moguću upotrebu za dobijanje biogoriva, bio-plastike itd.

Naravno, nisu sve ove primene jednako ekonomski isplative u slučaju naše države (i pokrajne), tako da je za odabir najisplativije upotrebe potrebno uraditi detaljnu LCA analizu, a to ipak izlazi iz okvira ovog rada.

\section{LITERATURA}

[1] M. Von Sperling, Biological Wastewater Treatment Vol. 1: Wastewater Characteristics, Treatment and Disposal, vol. 1. IWA Publishing, 2007.

[2] S. R. Smith, "Management, Use, and Disposal of Sewage Sludge," Waste Manag. Minimization, no. 2, 2009.

[3] Metcalf \& Eddy, Wastewater Engineering: Treatment and Resource Recovery, 5th Editio. McGraw-Hill Education, 2014.

[4] Cleverson Vitorio Andreoli, Marcos Von Sperling, Fernando Fernandes, and Mariska Ronteltap, Biological Wastewater Treatment Vol. 6: Sludge Treatment and Disposal. IWA Publishing, 2007.

[5] I. S. Turovskiū and P. K. Mathai, Wastewater sludge processing. Wiley-Interscience, 2006.

[6] S. Kolaković et al., "Istraživanje i razvoj modela sakupljanja i tretmana otpadnih voda kao podrška prostorno planskim dokumentima naselja i AP Vojvodine," 2013.

[7] Ellen Macarthur Foundation; McKinsey \& Company, "Growth within: a circular economy vision for a competitive europe," 2015. doi: Article.

[8] European Commission, "Communication from the Commission to the European Parliament, the Council, the European Economic and Social Committee and the
Committee of the Regions. Roadmap to a Resource Efficient Europe," 2012.

[9] "ISWA: Task Force Resource Management." https://www.iswa.org/iswa/iswa-groups/task-forces/taskforce-resource-management/ (accessed Apr. 20, 2020).

[10] D. Crutchik, N. Frison, A. L. Eusebi, and F. Fatone, "Biorefinery of cellulosic primary sludge towards targeted Short Chain Fatty Acids, phosphorus and methane recovery," Water Res., vol. 136, pp. 112-119, Jun. 2018, doi: 10.1016/j.watres.2018.02.047.

[11] Eurostat, "Sewage sludge production and disposal," 2402-2020, 2020.

https://appsso.eurostat.ec.europa.eu/nui/show.do?dataset= env_ww_spd\&lang=en (accessed Apr. 24, 2020).

[12] International Commission for the Protection of the Danube River (ICPDR), "Integrated Tisza River Basin Management Plan,” 2011.

\section{Kratka biografija:}

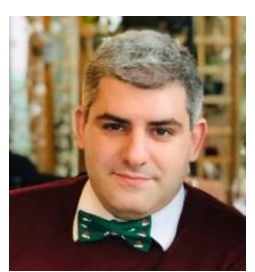

Marko Maravić - rođen je u Novom Sadu 1984. god. Osnovne (Bachelor) studije završio 2016. god. Master rad na Fakultetu tehničkih nauka iz oblasti inženjerstvo zaštite životne sredine odbranio je 2020.god.

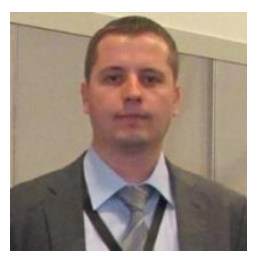

dr Srđan Kovačević - rođen je u Novom Sadu 1983. godine. Završio je Osnovnu školu "Žarko Zrenjanin" i Gimnaziju "Laza Kostić" u Novom Sadu. Fakultet tehničkih nauka u Novom Sadu upisao je 2002. godine, a 2008. godine je stekao zvanje diplomirani inženjer zaštite životne sredine - master. Doktorske akademske studije upisao je školske 2007/2008. god. na Fakultetu tehničkih nauka u Novom Sadu na studijskom programu Inženjerstvo zaštite životne sredine i položio sve ispite sa prosečnom ocenom 10. Doktorat pod naslovom "Analiza samoprečišćavajućeg potencijala podzemnih voda za uklanjanje farmaceutika primenom metode rečne obalske filtracije" odbranio je 2017. god.

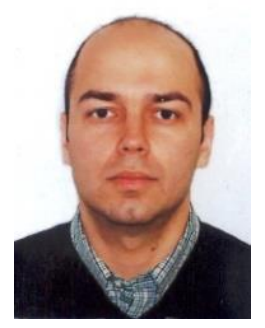

Prof. dr Nemanja Stanisavljević - rođen je u Boru. Fakultet tehničkih nauka u Novom Sadu smer inženjerstvo zaštite životne sredine, upisao je 2002. godine. Master rad odbranio 2007. godine na temu "Mogućnosti korišćenja gasova iz postrojenja za prečišćavanje otpadnih voda iz pivare MB". Iste godine upisao je prvu godinu doktorskih studija na Departmanu za Inženjerstvo zaštite životne sredine. Od 24.09.2018 zaposlen kao vanredni profesor na Fakultetu tehničkih nauka, Departman za Inženjerstvo zaštite životne sredine i zaštite na radu u Novom Sadu. 